\title{
SCALING ANALYSIS FOR THE DIRECT REACTOR AUXILIARY COOLING SYSTEM FOR FHR
}

\author{
Q. Lv ${ }^{\text {a }}$, X. Wang ${ }^{\text {a }}$, I.H. Kim ${ }^{\text {a }}$, X. Sun ${ }^{\text {a, } *, ~ R . N . ~ C h r i s t e n s e n ~}{ }^{\text {a }}$, T.E. Blue ${ }^{\text {a }}$, G. Yoder ${ }^{\text {, }}$, \\ D. Wilson ${ }^{\mathrm{b}}$, and P. Sabharwall ${ }^{\mathrm{c}}$ \\ ${ }^{a}$ Nuclear Engineering Program, Department of Mechanical \& Aerospace Engineering, \\ The Ohio State University, $201 \mathrm{~W} 19^{\text {th }}$ Avenue, Columbus, OH 43210, USA \\ ${ }^{\mathrm{b}}$ Oak Ridge National Laboratory, P.O. Box 2008, Oak Ridge, TN 37831, USA \\ ${ }^{c}$ Idaho National Laboratory, 2525 Fremont Avenue, Idaho Falls, ID 83415, USA \\ Email: lv.11@osu.edu,sun.200@osu.edu \\ *: Corresponding author; Tel: +1-614-247-7646; Fax: +1-614-292-3163
}

\begin{abstract}
The Direct Reactor Auxiliary Cooling System (DRACS) is a passive residual heat removal system proposed for the Fluoride-salt-cooled High-temperature Reactor (FHR) that combines the coated particle fuel and graphite moderator with a liquid fluoride salt as the coolant. The DRACS features three natural circulation/ convection loops that rely on buoyancy as the driving force and are coupled via two heat exchangers, namely, the DRACS Heat Exchanger and the Natural Draft Heat Exchanger. A fluidic diode is employed to minimize the parasitic flow into the DRACS primary loop and correspondingly the heat loss to the DRACS during reactor normal operation, and to activate the DRACS in accidents when the reactor is shut down.While the DRACS concept has been proposed, there are no actual prototypic DRACS systems for FHRs built or tested in the literature. In this paper, a detailed scaling analysis for the DRACS is performed, which will provide guidance for the design of scaled-down DRACS test facilities. Based on the Boussinesq assumption and one-dimensional flow formulation, the governing equations are non-dimensionalized by introducing appropriate dimensionless parameters. The key dimensionless numbers that characterize the DRACS system are obtained from the non-dimensional governing equations. Based on the dimensionless numbers and non-dimensional governing equations, similarity laws are proposed. In addition, a scaling methodology has been developed, which consists of a core scaling and a loop scaling. The consistence between the core and loop scaling is examined via the reference volume ratio, which can be obtained from both the core and loop scaling processes. The scaling methodology and similarity laws have been applied to obtain a scientific design of the scaled-down high-temperature DRACS test facility.
\end{abstract}




\section{KEYWORDS}

FHR, DRACS, scaling analysis, core scaling, loop scaling

\section{INTRODUCTION}

The Fluoride-salt-cooled High-temperature Reactor (FHR) is an advanced reactor concept that draws on four proven nuclear technologies, namely, the liquid salt of the Molten Salt Reactors (MSRs), the coated particle fuel (TRISO particle) of the High-temperature Gas-cooled Reactors (HTGRs), the pool configuration and passive safety system of the Sodium-cooled Fast Reactors (SFRs), and the Brayton power cycle technology [1, 2]. With the excellent thermal-physical properties of the liquid fluoride salts, the FHRs possess several potential benefits, including increased design margins, high operation temperature and low operation pressure, high core power density, and improved decay heat removal capability [3].

The Direct Reactor Auxiliary Cooling System (DRACS), as shown schematically in Figure 1, is a passive decay heat removal system proposed for FHRs. It features three coupled natural circulation/convection loops completely relying on buoyancy as the driving force. The DRACS Heat Exchanger (DHX) that is submerged in the reactor pool provides the coupling between the primary loop and secondary loop (DRACS loop). The Natural Draft Heat Exchanger (NDHX) sits at the bottom of an air chimney and dissipates heat from the secondary salt into the ambient air. One important component that has been proposed to preserve the passive feature of the DRACS is the fluidic diode in the primary loop. Fluidic diodes are passive flow control devices with low flow resistance in one flow direction and high flow resistance in the opposite direction. The fluidic diode is orientated in such a way that during reactor normal operation, the primary salt flow into 
the DRACS DHX is restricted, thus preventing excessive heat loss to the DRACS. However, when the DRACS is functioning during reactor accidents, the primary salt flow is in the forward flow direction of the diode, i.e., downward as shown in Figure 1 that features low flow resistance. Despite of its simple operation principle, the implementation of the fluidic diode into the pool downcomer can be complicated. In the SmAHTR DRACS design, the downcomer is partitioned into multiple zones and some special structure has to be employed to provide a smooth connection between a single zone and the fluidic diode top port [4]. Recently, a new concept has been proposed to eliminate the dedicated fluidic diode but use simpler structures, such as directional fins on the DHX tubing. This design will also help enhance the heat transfer in the DHX [5].

The concept of DRACS originated from Experimental Breeder Reactor-II (EBR-II), and had been widely adopted in many existing pool type Sodium-cooled Fast Reactor (SFR) designs, e.g., ABTR and KALIMER-600 [6]. The feasibility of DRACS concept was demonstrated with two representative tests carried out in EBR-II in 1986. In the first test, loss of flow was initiated without rector scram from the full power. The second test was a loss of heat sink without reactor scram from the full power. Both tests demonstrated that natural processes, such as natural convection of the primary coolant and heat conduction, were able to keep the core cooled without causing any failure [6].

\section{Figure 1: Schematic of the DRACS [7]}

Although many of the technologies involved in FHRs have been proven in different preceding reactor designs, no complete FHR-class design has yet been developed. It is proposed that the first FHR would necessarily be a test-scale reactor to validate the system attributes before proceeding 
to larger and commercial systems [7]. Recently, Massachusetts Institute of Technology (MIT), University of California at Berkeley (UCB) and University of Wisconsin Madison (UW) are pursuing a test-scale FHR design that can be deployed in the near future under an Integrated Research Project (IRP) [8]. This test-scale FHR features a thermal power of about 20 MWth. DRACS, as the passive decay heat removal system, should also be tested for its integral thermal performance in this test-scale FHR. Currently, efforts of designing, testing, and modelling the DRACS for a 20-MWth FHR is being carried out at The Ohio State University (OSU) independent of the IRP effort. A modular prototypic DRACS design that is capable of removing $1 \%$ (200 kW) of the nominal core power has been proposed $[9,10]$. This DRACS design features a total height of $15 \mathrm{~m}$ and is therefore challenging to be accommodated in a laboratory testing environment. Scaling analysis is therefore required to guide the design of scaled-down facilities, which are expected to reproduce key phenomena in the prototypic DRACS system.

Scaling analysis and similarity laws for single-phase forced flows have been well established. However, scaling analysis for natural circulation/convection is more challenging due to the coupling of the driving force of flow and heat transfer process [11]. For the DRACS system, scaling analysis is even more complicated because there are three coupled natural circulation/convection loops. Integral effects of the coupled natural circulation/convection loops should be considered in order to develop meaningful similarity laws. There has been preceding work focusing on molten salt scaling by Bardet and Peterson $[12,13]$. They derived the dimensionless numbers and developed the scaling laws by non-dimensionalizing the governing differential equations for mass, momentum, and energy conservation, and the associated boundary and initial conditions. In the present work, however, general similarity criteria for single-phase natural convection by Ishii and Kataoka [11], are examined which are based on the integral format 
of the governing equations and boundary conditions. A scaling methodology on how to apply the general similarity criteria to the DRACS is subsequently developed, which consists of the core scaling and loop scaling. A scientific design of a scaled-down high-temperature DRACS test facility (HTDF) is finally developed by applying the developed scaling methodology and similarity laws.

\section{THE MODULAR PROTOTYPIC DRACS DESIGN}

There has been prior work on FHR DRACS design and evaluation performed by Greene et al. at ORNL [4]. However, their work is based on their 125-MWth SmAHTR design, which is out of our scope. A modular loop-type DRACS prototypic design for a 20-MWth test-scale FHR has been developed at the OSU $[9,10]$, as illustrated in Figure 2. This DRACS design has a capacity of 200 $\mathrm{kW}$, corresponding to $1 \%$ of the nominal core power. The major components involved in the DRACS are the reactor core, two heat exchangers, fluidic diode, air chimney, and piping. This design assumes FLiBe ( ${ }^{7} \mathrm{LiF}-\mathrm{BeF} 2,66-34$ in mol\%) and FLiNaK (LiF-NaF-KF, 46.5-11.5-42 in mol\%) as the primary and secondary coolants, respectively, due to their superior thermal properties. Lithium in the $\mathrm{FLiBe}$ has to be enriched to more than $99.995 \%{ }^{7} \mathrm{Li}$ to provide a large moderating ratio and small coolant parasitic capture probability. Ambient air is the ultimate heat sink for the DRACS.

\section{Figure 2: Prototypic design of the DRACS}

The prototypic reactor design adopted a pebble-bed core design, FHR-16, which was proposed by Peterson [14]. In spite of the current IRP effort in developing a test-scale FHR [8], FHR-16 was 
the only design with detailed core dimensions when this study was initiated. In addition, no detailed pool design was ever developed even for the FHR-16, which prevented us from having a pool-type but loop-type design. In contrast to the conventional 6-cm diameter homogeneous pebbles, this core design utilizes 3-cm diameter annular fuel pebbles, which will lead to better heat transfer between the pebbles and coolant, and lower peak temperature in the pebbles [14].

The two heat exchangers, namely, the DRACS Heat Exchanger (DHX) and the Natural Draft Heat Exchanger (NDHX) that couple the three natural circulation/convection loops are directly related to the integral thermal performance of the DRACS. Shell-and-tube heat exchangers, due to their low pressure drops and mature manufacturing technologies have been proposed for the DHX and NDHX. Standard Delaware Method [15] that is well developed for design of shell-and-tube heat exchangers has been applied. For the DHX, the design calls for 196 1.21-m long BWG-18 straight tubes that are placed in a staggered triangular array. Four baffles with a baffle cut of $25 \%$ are employed to enhance the shell-side heat transfer. For the NDHX, 100 1.93-m long BWG-18 straight tubes have been used, which are laid out in a staggered triangular pattern in two layers. Both of the DHX and NDHX are capable of removing $200 \mathrm{~kW}$ heat and adopt Hastelloy N as the construction material.

To prevent excessive heat loss into the DRACS during reactor normal operation, a fluidic diode has been employed in the DRACS primary loop. A fluidic diode is a passive flow control device with low flow resistance in one flow direction and high flow resistance in the opposite flow direction. A conventional vortex diode that has been tested by Chikazawa et al. [16] is adopted in the design. The fluidic diode has been oriented such that the flow will be in its reverse flow direction (upward direction in Figure 2) during reactor normal operation. This parasitic upward flow through the fluidic diode and the DHX will be scaled properly to prevent the secondary salt 
from freezing. When the natural circulation of the primary salt is established following some accidents, e.g. loss of forced coolant accident (LOFC), the flow will be in the forward flow direction of the fluidic diode, experiencing significantly smaller resistance.

An annular air chimney constructed from reinforced concrete has been proposed in the prototypic DRACS design. The air enters the chimney through four louvers near the top of the chimney. It subsequently flows downward through the annulus and finally leaves the chimney through the thermally insulated inner duct. The NDHX sits near the bottom of the chimney, transferring heat from the secondary salt on the tube side to the surrounding air. A summary of the design of the prototypic DRACS is given in Table 1.

\section{Table 1: Design results of the prototypic DRACS}

\section{DEVELOPMENT OF THE SIMILARITY CRITERIA AND SCALING METHODOLOGY}

\section{Governing Equations}

The principle of the scaling analysis is to non-dimensionalize the governing equations of the DRACS by introducing appropriate dimensionless parameters. In the scaling analysis, the Boussinesq approximation has been applied, which states that the fluid is incompressible except in the gravity term in the momentum equation. With this assumption, the one-dimensional governing equations for a single-phase fluid are given as $[11,17]$ :

Continuity equation:

$$
u_{i} a_{i}=u_{r} a_{0}
$$

Integral momentum equation: 


$$
\rho \frac{\mathrm{d} u_{r}}{\mathrm{~d} t} \sum_{i}\left(\frac{a_{0}}{a_{i}} l_{i}\right)=g \rho \oint \beta\left(T-T_{0}\right) \mathrm{d} z-\frac{\rho u_{r}^{2}}{2} \sum_{i}\left(\frac{f l}{d}+K\right)_{i}\left(\frac{a_{0}}{a_{i}}\right)^{2}
$$

Fluid energy equation for the $i^{\text {th }}$ section:

$$
\rho c_{p}\left\{\frac{\partial T}{\partial t}+u \frac{\partial T}{\partial z}\right\}=\frac{4 h}{d}\left(T_{s}-T\right)
$$

Solid energy equation for the $i^{\text {th }}$ section:

$$
\rho_{s} c_{p s} \frac{\partial T_{s}}{\partial t}-k_{s} \nabla^{2} T_{s}-\dot{q}_{s}=0
$$

The boundary condition at the interface between the fluid and structure in the $i^{\text {th }}$ section is given as:

$$
-k_{s} \frac{\partial T_{s}}{\partial y}=h\left(T_{s}-T\right)
$$

Here, subscripts $i, r, 0$, and $s$ are the $i^{\text {th }}$ component, representative variable, reference constant value, and solid structure, respectively; Variables $u, a, \rho, t, l, \beta, T, g, f, K, d, c_{p}, h, k$, and $\dot{q}$ are the velocity, flow cross-sectional area, density, time, axial length, thermal expansion coefficient, temperature, gravitational acceleration, friction factor, form loss factor, hydraulic diameter, specific heat capacity, heat transfer coefficient, thermal conductivity, and volumetric heat generation rate, respectively. The transverse and axial coordinates are denoted by $y$ and $z$, respectively.

The steady-state fluid velocity and temperature difference between the hot leg and cold leg in each loop are chosen to define the dimensionless parameters, as summarized in Table 2. Here, the hydraulic diameter $d$ and conduction depth $\delta$ are respectively defined as $d=4 a / \xi$ and $\delta=a_{s} / \xi$, where $\xi$ and $a_{s}$ are the wetted perimeter and cross-sectional area of the structure, respectively. 


\section{Table 2: Definitions of dimensionless parameters}

The non-dimensional governing equations are obtained by introducing the dimensionless parameters in Table 2 into Eqs. (1)-(5) as:

$$
\begin{gathered}
U_{i} A_{i}=U_{r}, \\
\frac{\mathrm{d} U_{r}}{\mathrm{~d} \tau}\left(\sum_{i} \frac{L_{i}}{A_{i}}\right)=\mathrm{R}\left\lceil\theta \mathrm{d} Z-\frac{U_{r}^{2}}{2}\left(\sum_{i} \frac{\mathrm{F}_{i}}{A_{i}^{2}}\right),\right. \\
\frac{\partial \theta_{i}}{\partial \tau}+\frac{U_{r}}{A_{i}} \frac{\partial \theta_{i}}{\partial Z}=\mathrm{St}_{i}\left(\theta_{s i}-\theta_{i}\right) \\
\frac{\partial \theta_{s i}}{\partial \tau}-\mathrm{T}_{i}^{*} \nabla_{i}^{* 2} \theta_{s i}-\mathrm{Q}_{s i}=0 \\
\frac{\partial \theta_{s i}}{\partial Y_{i}}=\mathrm{Bi}_{i}\left(\theta_{i}-\theta_{s i}\right)
\end{gathered}
$$

where the dimensionless numbers are defined as:

Richardson number: $\mathrm{R} \equiv \frac{\beta g \Delta T_{0} l_{0}}{u_{0}^{2}}$,

Friction number: $\mathrm{F}_{i} \equiv\left(\frac{f l}{d}+K\right)_{i}$,

Stanton number: $\mathrm{St}_{i} \equiv\left(\frac{4 h l_{0}}{\rho c_{p} u_{0} d}\right)_{i}$,

Time ratio number: $\mathrm{T}_{i}^{*} \equiv\left(\frac{\alpha_{s}}{\delta^{2}} \frac{l_{0}}{u_{0}}\right)_{i}$, 
Heat source number: $\mathrm{Q}_{s i} \equiv\left(\frac{\dot{q}_{s} l_{0}}{\rho_{s} c_{p s} u_{0} \Delta T_{0}}\right)_{i}$

Biot number: $\mathrm{Bi}_{i} \equiv\left(\frac{h \delta}{k_{s}}\right)_{i}$.

Here, $\alpha_{s}$ is thermal diffusivity of the solid.

\section{Similarity Criteria}

The similarity criteria between the prototype and model are established based on the aforementioned non-dimensional governing equations, i.e., Eqs. (6)-(10). They are summarized as follows:

$$
\begin{gathered}
\left(\sum_{i} L_{i} / A_{i}\right)_{R}=1, \\
\left(\sum_{i} \mathrm{~F}_{i} / A_{i}^{2}\right)_{R}=\left[\sum_{i}\left(f_{i} \frac{l_{i}}{d_{i}}+K_{i}\right) /\left(a_{i} / a_{0}\right)^{2}\right]_{R}=1, \\
\mathrm{R}_{R}=\left(\beta \Delta T_{0} l_{0} / u_{0}^{2}\right)_{R}=1, \\
A_{i R}=\left(a_{i} / a_{0}\right)_{R}=1, \\
\mathrm{St}_{i R}=\left(h l_{0} / \rho c_{p} u_{0} d\right)_{i R}=1, \\
\mathrm{Bi}_{i R}=\left(h \delta / k_{s}\right)_{i R}=1, \\
\mathrm{~T}_{i R}^{*}=\left(\alpha_{s} l_{0} / \delta^{2} u_{0}\right)_{i R}=1, \\
\mathrm{Q}_{s i R}=\left(\dot{q}_{s} l_{0} / \rho_{s} c_{p s} u_{0} \Delta T_{0}\right)_{i R}=1 .
\end{gathered}
$$


where the subscript $R$ denotes the ratio of a property between the model and the prototype, for example $A_{i R}=\frac{A_{i, \text { model }}}{A_{i, \text { prototype }}}$. Equations (11)-(13) are the requirements considering the entire primary/secondary loop of the DRACS. Equations (14)-(17) are applied to each individual component in each of the loops. Equation (18) includes the power density and is only applicable to the core.

Considering the steady-state momentum and energy conservation of the entire loop, the ratios for the reference velocity and temperature difference are given as:

$$
\begin{aligned}
\left(u_{0}\right)_{R} & =\left(\frac{\beta l_{0} \dot{Q}}{\rho c_{p} a_{0}}\right)_{R}^{1 / 3}, \\
\left(\Delta T_{0}\right)_{R} & =\left(\frac{\dot{Q}}{\rho c_{p} u_{0} a_{0}}\right)_{R} .
\end{aligned}
$$

Here, $\dot{Q}$ is the total decay power. It should be noted that the requirement related to the Richardson number is satisfied automatically if Eqs. (19) and (20) are met.

The ratios for the hydraulic diameter, heat transfer coefficient, and conduction depth for each component based on the requirements in Eqs. (15)-(17) are provided as:

$$
\begin{gathered}
\left(d_{i}\right)_{R}=\left(\frac{\rho_{s} c_{p s}}{\rho c_{p}}\right)_{i R}\left(\frac{\alpha_{s i} l_{0}}{u_{0}}\right)_{R}^{1 / 2}, \\
\left(h_{i}\right)_{R}=\left(k_{s i}\right)_{R}\left(\frac{u_{0}}{l_{0} \alpha_{s i}}\right)_{R}^{1 / 2}, \\
\left(\delta_{i}\right)_{R}=\left(\frac{\alpha_{s i} l_{0}}{u_{0}}\right)_{R}^{1 / 2} .
\end{gathered}
$$




\section{Scaling Methodology}

For the primary loop scaling, there are two relations, i.e., Eqs. (19) and (20), but five unknowns, i.e., $\left(u_{0}\right)_{R},\left(l_{0}\right)_{R},\left(a_{0}\right)_{R},\left(\Delta T_{0}\right)_{R}$, and $(\dot{Q})_{R}$. To close the equation system, three additional relations need to be provided via assumptions. Two degrees of freedom are removed with assumptions on the power and loop height ratios, recognizing the constraints on the electric heater power and space available for the scaled-down facility. To date, the only component that has a relatively detailed and perhaps mature design in the prototypic design is the pebble bed core while designs of other components are relatively flexible. In addition, the core, as the heat source, is directly related to how quickly the natural circulation will be established in the primary loop. Therefore, the third assumption has been made via the analysis of the core.

According to Eq. (22), the convection time ratio is formulated as:

$$
\left(\frac{l_{0}}{u_{0}}\right)_{R}=\left(\frac{k_{s} \rho_{s} c_{p s}}{h^{2}}\right)_{R}
$$

The time ratio in the primary loop is therefore determined based on the information on the heat transfer coefficient and structure material of the core in both the prototype and the experiment. This enables us to complete the core and primary loop scaling, as illustrated in Figure 3. With the core geometry specified, the product of the loop height ratio and pipe area ratio (i.e., the reference volume ratio) can be calculated using Eq. (18) along with Eq. (20). In addition, the reference volume ratio can also be obtained upon the completion of the primary loop scaling. The heat source number matches if the evaluated values of this product from the two approaches are the same. 


\section{Figure 3: Flow charts for the core and primary loop scaling}

For the secondary loop scaling, the same set of equations are applied, but the number of unknowns is reduced to three, compared to five in the primary loop scaling. The reason is that one unknown, $(\dot{Q})_{R}$, denoting the heat removed by the secondary loop, is the same as that by the primary loop at steady state, assuming that the heat loss is negligible. In addition, the primary and secondary loops are coupled through the DHX, as shown in Figure 2. Starting with the definition of the conduction depth, this coupling can be mathematically expressed as:

$$
\frac{\left(\frac{l_{0}}{u_{0}}\right)_{R_{-} \text {Loop } 1}}{\left(\frac{l_{0}}{u_{0}}\right)_{R_{-} \text {Loop } 2}}=\left(\frac{d}{d+2 t}\right)_{R}^{2},
$$

where $d$ and $t$ are the tube inner diameter and tube wall thickness in a shell-and-tube type DHX, respectively. Therefore, the convection time ratio for the two loops will need to be approximately the same if the thickness of the tubes of the DHX is considerably smaller compared to the tube inner diameter. As a result, the loop height ratio is the only assumed parameter for the secondary loop scaling. The flow chart for the primary loop scaling can then be applied to the secondary loop as well.

For the air loop, the scaling analysis is similar to that of the secondary loop, but with one difference due to the fact that the air loop is not closed. An additional form loss term due to the kinetic energy difference between the incoming and outgoing air streams should be added to the integral momentum equation. Other than this difference, the same scaling procedure as discussed earlier applies. 
For the DRACS, the pressure drops in the primary, secondary, and air loops play a key role in the development of the natural circulation/convection flows, and therefore the overall decay heat removal performance. Equation (12) dictates the requirement on the scaling of the total pressure drop including the friction and form loss for each loop in a flexible form that gives some freedom to adjust the pressure drop distribution over the various components. However, for the main pressure drop contributor, e.g., the fluidic diode, it is recommended to preserve the term ( F/ $\left.A^{2}\right)$ by carefully scaling the flow path length, hydraulic diameter, and flow area, and correspondingly the friction factor and form loss coefficient. It should be noted that although the friction factor and from loss coefficient depend on local Re number, there is no strict requirement that the Re be preserved between the experiment and prototype, as long as $\left(\mathrm{F} / \mathrm{A}^{2}\right)$ is preserved. This provides some convenience for the scaling when the basic geometry of a component changes from the prototype to the experiment, e.g., from a pebble-bed core to a prismatic core.

As the heat transfer in the core, DHX, and NDHX are important, Eqs. (21)-(23) should be applied. Requirement on the scaling of the heat transfer coefficient is given in Eq. (22), which can be satisfied by adjusting the geometry and correspondingly the local Re number. Similar to the previous discussion on the pressure drop scaling, there is not strict requirement imposed on the local Re number. Upon completion of the component scaling, Eqs. (11) and (12) should be examined for the primary and secondary loops, respectively. If these requirements are not met, some compromise will need to be made in the scaling of certain components. 


\section{SCALING ANALYSIS FOR THE HTDF}

\section{Core Scaling Analysis}

The previously discussed scaling methodology and similarity laws are applied to the HTDF, starting with the core scaling. Heat transfer and properties of the structural materials in the core are first analyzed. The heat transfer in a pebble bed core could be dominated by the natural, forced, or mixed convection, depending on the Reynolds and Grashof numbers of the flow, which are respectively defined as:

$$
\begin{gathered}
\mathrm{Re} \equiv \frac{D_{p} G}{\mu}, \\
\mathrm{Gr} \equiv \frac{g \beta \square T D_{p}^{3}}{v^{2}} .
\end{gathered}
$$

Here, $D_{p}, G, \mu$, and $\nu$ are the pebble diameter, mass flux, dynamic viscosity and kinematic viscosity of the fluid, respectively. The Reynolds number in the core defined in Eq. (26) is estimated as 3.9 when $1 \%$ decay power is assumed for a 20 -MWth prototypic FHR. This is far below the application ranges of most heat transfer correlations available for a pebble bed core in the literature. In view of this, the mass transfer correlations for low Reynolds numbers proposed by Karabales et al. [18] are adopted by analogies between the Sherwood number and the Nusselt number, and the Schmidt number and the Prandtl number. The Nusselt number for different flow regimes are given as [18]:

Mixed laminar convection: 


$$
\mathrm{Nu}=\left[\left\{0.46(\mathrm{Gr} \operatorname{Pr})^{1 / 4}\right\}^{6}+\left\{4.58 \operatorname{Re}^{1 / 3} \operatorname{Pr}^{1 / 3}\right\}^{6}\right]^{1 / 6}
$$

Mixed turbulent convection:

$$
\mathrm{Nu}=\left[\left\{0.112(\mathrm{Gr} \operatorname{Pr})^{1 / 3}\right\}^{2}+\left\{2.39 \operatorname{Re}^{0.56} \operatorname{Pr}^{1 / 3}\right\}^{2}\right]^{1 / 2},
$$

Forced convection:

$$
\mathrm{Nu}=\left[\left\{4.58 \operatorname{Re}^{1 / 3} \operatorname{Pr}^{1 / 3}\right\}^{6}+\left\{2.39 \operatorname{Re}^{0.56} \operatorname{Pr}^{1 / 3}\right\}^{6}\right]^{1 / 6}
$$

The relation between the Reynolds and Grashof numbers when the flow transitions from the mixed to forced convection can be obtained from the above Nusselt number correlations, as shown in Figure 4. In the present case, the Reynolds and Grashof numbers are 3.9 and $4.6 \times 10^{5}$ at the nominal conditions, respectively, leading to a mixed laminar flow condition. The Nusselt number is 22.1 based on Eq. (28) and the convective heat transfer coefficient is $832 \mathrm{~W} / \mathrm{m}^{2}-\mathrm{K}$ when FLiBe is used as the primary coolant.

Figure 4: Relation between the critical Reynolds and Grashof numbers for flow transition from the mixed to forced convection

Figure 5 shows the annular fuel pebble that has been proposed in the prototypic core design [14]. TRISO particles are embedded in the spherical shell with high-density graphite as the binder. The low-density graphite enclosed in the central region can adjust the overall density of the pebble. The detailed dimensions of the pebble and the TRISO particle are summarized in Table 3.

Figure 5: The structure of the fuel pebble and TRISO particle [14] 
The effective properties of such pebbles are evaluated based on the properties of the materials composing the fuel pebbles. The TRISO particle has been well studied and the properties of the various materials in a TRISO particle have been summarized by Gougar et al. [19]. However, limited studies were found for the matrix graphite, i.e., the high-density graphite coating and the filling graphite in the fuel spherical shell. In the present analysis, the same matrix graphite is used as in the HTGRs. The properties of the constituent materials depend on their temperature and were evaluated at a reference temperature of $750{ }^{\circ} \mathrm{C}$ per Griveau's study [20]. In addition, the thermal conductivity of the matrix graphite was also found to be a function of the received neutron fluence. The thermal conductivities at the room temperature and $1000^{\circ} \mathrm{C}$ without any neutron fluence are found to be 62 and $35 \mathrm{~W} / \mathrm{m}-\mathrm{K}$, respectively [21, 22]. The thermal conductivity of the matrix graphite at $750^{\circ} \mathrm{C}$ is obtained by a linear interpolation. The dependence of the matrix graphite thermal conductivity on the neutron fluence is found from Ahlf's study [23].

\section{Table 3: Dimensions of the fuel pebble and the TRISO particle}

Volumetric averaging and mass-weighted averaging were respectively performed to evaluate the effective density and specific heat capacity for the fuel pebbles. The determination of the effective thermal conductivity is slightly complicated and consists of two steps. First, the empirical German relationship [24] is used to calculate the effective thermal conductivity for the spherical fuel shell:

$$
k_{\text {shell }}=1.2768\left(\frac{-0.3906 \times 10^{-4} T+0.06829}{D O S I S+1.931 \times 10^{-4} T+0.105}+1.228 \times 10^{-4} T+0.042\right) \text {, }
$$


where $k_{\text {shell }}$ is the effective thermal conductivity of the spherical fuel shell in $\mathrm{W} / \mathrm{cm}-\mathrm{K} ; T$ is the fuel temperature in ${ }^{\circ} \mathrm{C}$; and $\operatorname{DOSIS}$ is the neutron fluence in $10^{21} \mathrm{n} / \mathrm{m}^{2}$. Secondly, a volume-based harmonic average is performed over the spherical fuel shell and the high-density graphite coating by considering that the two layers are in series and the total thermal resistance should be the summation of the individual layers. The effective thermal conductivity of the entire pebble, $k_{\text {pebble }}$ is thus calculated as:

$$
k_{\text {pebble }}=\frac{V_{\text {shell }}+V_{\text {coating }}}{V_{\text {shell }} / k_{\text {shell }}+V_{\text {coating }} / k_{\text {coating }}} .
$$

The calculated effective properties of the fuel pebbles are given in Table 4 .

\section{Table 4: Effective properties of the fuel pebbles}

The next step is to evaluate the heat transfer coefficient and structure properties in the core of the HTDF. Figure 6 shows the core design in the HTDF, which consists of seven electric heater rods arranged in an equilateral triangular pattern in a circular vessel. The flow channels are categorized into interior sub-channels (type I) and wall sub-channels (type II). Heat transfer coefficients for such an arrangement are obtained by Mohanty and Sahoo [25, 26] and Todreas and Kazimi [27]. The design with $P / D$ of 1.6 and $W / D$ of 1.4 is adopted since this configuration results in a large Nusselt number for the wall sub-channel. Here, $P, W$, and $D$ are the rod pitch, shell-to-wall spacing, and rod diameter, respectively. The effective heat transfer coefficient in the core is calculated by an area-weighted averaging.

Figure 6: Core design in the HTDF 
Different core geometries (by varying the heater diameter $D$ ) and different sheath materials for the electric heaters (ranging from ceramics to alloys) have been examined. It is found that the loop scaling results would vary significantly with the core geometry and sheath material selections. The trend of the variation is that, with more compact core design and less thermally conductive material for the heater sheath, the core and loop scaling results will generally better satisfy the scaling analysis requirements. A speculation reveals that the "prismatic" core design used in the experiment is inferior to the prototypic pebble bed core in heat transfer. Thus the core in the scaled-down experiment needs to be more compact to increase the heat transfer. Also, due to the deteriorated heat transfer in the experiments, the convection process becomes less effective. Correspondingly, the conduction process in the heat source should also be inhibited, which requires the use of less thermally conductive material as the sheath for the electric heaters. Out of the extensively examined cases, one promising case (not necessarily the best) dictates the core design summarized in Table 5. With FLiNaK selected as the primary coolant, the area-based average heat transfer coefficient was found to be $251 \mathrm{~W} / \mathrm{m}^{2}-\mathrm{K}$. The sheath of the heater consists of a 0.8-mm layer of YTZP ceramic cladded with a $0.4-\mathrm{mm}$ thick Hastelloy $\mathrm{N}$ outer layer. YTZP is one kind of Zirconia ceramic that features thermal conductivity as low as $2.2 \mathrm{~W} / \mathrm{m}-\mathrm{K}$ [28].

\section{Table 5: Design parameters of the core in the HTDF}

With all the necessary information, the convection time ratio is obtained and a complete scaling analysis of the DRACS is accomplished by applying the developed scaling methodology and similarity laws. The scaling results, as summarized in Tables 6-8, will be discussed in the 
following session. In the scaling analysis, $\mathrm{KF}^{-\mathrm{ZFF}_{4}}$ (58-42 in mol\%) with a low melting point $\left(390^{\circ} \mathrm{C}\right)$ is selected as the secondary coolant and Inconel 600 is assumed as the construction material for the DHX and NDHX.

\section{Table 6: Core and loop scaling results for the HTDF}

As shown in Table 6, the results corresponding to a fresh prototypic core, highlighted in bolds, appear to be the closest in satisfying the scaling analysis requirements. When the heat transfer coefficient in the core is determined, the core geometry must be specified, from which the hydraulic diameter ratio can be calculated. Meanwhile, the hydraulic diameter ratio in the core can be obtained from the core scaling requirement. As can be seen, the two values for the hydraulic diameter ratio in the core do not match well ( 0.38 as required by the scaling analysis vs. 2.14 from the actual design), which will cause distortion in the Stanton number and correspondingly distortion in the interfacial temperature simulation [11]. In addition, the heat source number ratio is much larger than one, which will cause higher peak temperature in the core in the experiments. However, this problem can be mitigated by adjusting the power provided by the heaters. For the DHX and NDHX scaling, most of the ratios are close to one as seen from Table 7. Therefore, the designs of the DHX and NDHX in the HTDF should have dimensions similar to those in the prototypic design.

Table 7: DHX and NDHX scaling results for the HTDF 
No exotic results have been encountered in the loop scaling, as can be seen from Table 8, which ensures successful operation of the circulation loops. It should be noted that the scaling results presented here just give a reference design. The core design based on the core scaling results seems feasible. However, there might be engineering difficulties with the construction of the core, e.g., using ceramic as the sheath for the heaters, and fitting small heater rods into the compact vessel. If the difficulties cannot be resolved and as a consequence the core design has to be modified, the convection time ratio obtained here is recommended to be retained since it yields good heat exchanger and loop scaling results, which are key in ensuring successful operation of the circulation loops and the integral performance of the DRACS.

\section{Table 8: Design results summary for the HTDF}

\section{CONCLUSIONS}

In the present study, a detailed scaling analysis for the proposed DRACS for FHRs has been performed. Similarity laws are obtained by non-dimensionalizing the governing equations for the DRACS with appropriate dimensionless parameters. A scaling methodology that consists of the core scaling and loop scaling has also been developed. The scaling methodology and similarity laws are subsequently applied to a modular prototypic DRACS design for a 20-MWth FHR to obtain a scientific design of a high-temperature DRACS test facility. The scaling results for the HTDF appear sound except for the distortions in the Stanton number and heat source number in the core, which would cause distortions in the interfacial temperature simulation of the electrical heater rods in the experiments. These distortions are however not critical due to the objectives of 
the experiments, as long as the maximum heater rod surface temperature stay below the sheath failure temperature.

A reference scientific design for the HTDF based on the scaling results can be utilized as a starting point of an actual test facility. However, as can be imagined, various engineering challenges will be encountered, mainly due to the high-temperature attribute of the HTDF. When such situation occurs, compromises will have to be made in some scaling laws.

\section{ACKNOWLEDGMENTS}

The authors would like to acknowledge the financial support from the U.S. Department of Energy Nuclear Energy University Program (NEUP). Dr. David Holcomb of the Oak Ridge National Laboratory provided valuable comments and is much appreciated. 


\section{REFERENCES}

1. Forsberg, C.W., "The Advanced High-Temperature Reactor: High-Temperature Fuel, Liquid Salt Coolant, and Liquid-Metal-Reactor Plant," Progress in Nuclear Energy, 47(1-4), pp. $32-43,2005$.

2. Bardet, P.M., Blandford, E., Fratoni, M., Niquille, A., Greenspan, E., and Peterson, P.F., "Design, Analysis and Development of the Modular PB-AHTR," Proc. of ICAPP'08, Anaheim, CA, June 8-12, 2008.

3. Forsberg, C.W., Pickard, P. and Peterson, P.F., "Molten-Salt-Cooled Advanced High-Temperature Reactor for Production of Hydrogen and Electricity," Nuclear Technology, 144, pp. 289-302, 2003.

4. Greene, S.R., Gehin, J.C., Holcomb, D.E., Carbajo, J.J., Ilas, D., Cisneros, A.T., Varma, V.K., Corwin, W.R., Wilson, D.F., Yoder, G.L., Qualls, A.L., Peretz, F.J., Flanagan, G.F., Clayton, D.A., Bradley, E.C., Bell, G.L., Hunn, J.D., Pappano, P.J., and Cetiner, M.S., "Pre-Conceptual Design of a Fluoride-Salt-Cooled Small Modular Advanced High-Temperature Reactor (SmAHTR),” ORNL/TM-2010/199, Oak Ridge National Laboratory, Oak Ridge, TN, December, 2010.

5. Holcomb, D.E., Flanagan, G.F., Mays, G.T., Pointer, W.D., Robb, K.R., and Yoder, G.L., "Fluoride Salt-Cooled High-Temperature Reactor Technology Development and Demonstration Roadmap,” ORNL/TM-2013/401, Oak Ridge National Laboratory, Oak Ridge, TN, September, 2013. 
6. Zhang, H., Zhao, H., Mousseau, V., and Szilard, R., "Design Considerations for Economically Competitive Sodium Cooled Fast Reactors," Proc. of ICAPP'09, Tokyo, Japan, May 10-14, 2009.

7. Holcomb, D.E., Cetiner, S.M., Flanagan, G.F., Peretz, F.J., Yoder, G.L., and Jr., “An Analysis of Testing Requirements for Fluoride Salt-cooled High Temperature Reactor Components," ORNL/TM-2009/297, Oak Ridge National Laboratory, Oak Ridge, TN, November, 2009.

8. Forsberg, C.W., Hu, L., Peterson, P.F., and Allen, T., "Fluoride-Salt-Cooled High-Temperature Reactors (FHRs) for Power and Process Heat," MIT-ANP-143 (Rev 0), Massachusetts Institute of Technology, Cambridge, MA, 2012.

9. Wang, X., Lv, Q., Sun, X., Christensen, R.N., Blue, T.E., Yoder, G., Wilson, D., and Sabharwall, P., “A Modular Design of a Direct Reactor Auxiliary Cooling System for AHTRs," Transaction of the American Nuclear Society, American Nuclear Society 2011 Annual Meeting, Hollywood, FL, June 26-30, 104, pp. 1077-1080, 2011.

10. Lv, Q., "Scaling Analysis for the Direct Reactor Auxiliary Cooling Systems for AHTRs," Master Thesis, The Ohio State University, Columbus, OH, 2012.

11. Ishii, M. and Kataoka, I., "Scaling Laws for Thermal-Hydraulic System under Single Phase and Two-Phase Natural Circulation," Nuclear Engineering and Design, 81, pp. 411-425, 1984.

12. Bardet, P.M., and Peterson, P.F., "Scaling Options for Integral Experiments for Molten Salt Fluid Mechanics and Heat Transfer," 11th International Topical Meeting on Nuclear Reacotr Thermal Hydraulics (Nureth 11), Avignon, France, October 2-6, 2005.

13. Bardet, P.M., and Peterson, P.F., “Options for Scaled Experiments for High Temperature Liquid Salt and Helium Fluid Mechanics and Converctive Heat Transfer," Nuclear Technology, 163, pp. 344-357, 2008. 
14. Peterson, P.F., "Modular Pebble-Bed AHTR Design Review,” Design Status Update, University of California at Berkeley, Berkeley, CA, October 7, 2009.

15. Hewitt, G.F., Handbook of Heat Exchanger Design, Chapter 3.3, Begell House, Inc., Wallingford, 1992.

16. Chikazawa, Y., Aizawa, K., Shiraishi, T., and Sakata, H., "Experimental Demonstration of Flow Diodes Applicable to a Passive Decay Heat Removal System for Sodium-Cooled Reactors," Journal of Nuclear Science and Technology, 46(4), pp. 321-330, 2009.

17. Vijayan, P.K. and Austregesilo, H., "Scaling Laws for Single-phase Natural Circulation Loops," Nuclear Engineering and Design, 152, pp. 331-347, 1994.

18. Karabales, A.J., Wegner, T.H., and Hanratty, T.J., "Use of Asymptotic Relations to Correlate Mass Transfer Data in Packed Beds," Chemical Engineering Science, 26, pp. 1581-1589, 1971.

19. Gougar, H., et al., "Prismatic Coupled Neutronics/Thermal Fluids Transient Benchmark of the MHTGR-350 MW Core Design - Benchmark Definition," accesed from INL published material website, 2010.

20. Griveau, A., "Modeling and Transient Analysis for the Pebble Bed Advanced High Temperature Reactor (PB-AHTR)," UCBTH-07-001, University of California at Berkeley, Berkeley, CA, 2007.

21. Sato, S., Kurumada, A., Kawamata, K., and Suzuki, N., "Fracture Mechanical Properties and Neutron Irradiation Effects of Fuel Compacts for the HTTR," Nuclear Engineering and Design, 141, pp. 395-408, 1993. 
22. Tang, C., Tang, Y., Zhu, J., Zou, Y., Li, J., and Ni, X., "Design and Manufacture of the Fuel Element for the 10 MW High Temperature Gas-cooled Reactor," Nuclear Engineering and Design, 218, pp. 91-102, 2002.

23. Ahlf, J., Conrad, R., Cundy, M., and Scheurer, H., "Irradiation Experiments on High Temperature Gas-cooled Reactor Fuels and Graphites at the High Flux Reactor Petten," Journal of Nuclear Materials, 171, pp. 31-36, 1990.

24. Gao, Z., and Shi, L., "Thermal Hydraulic Calculation of the HTR-10 for the Initial and Equilibrium Core," Nuclear Engineering and Design, 218, pp. 51-64, 2002.

25. Mohanty, A.K. and Sahoo, K.M., "Laminar Convection in Wall Sub-Channel and Transport Rates for Finite Rod-Bundle Assemblies by Superposition," Nuclear Engineering and Design, 92, pp. 169-180, 1986.

26. Sahoo, K.M. and Mohanty, A.K., "Finite Element Analysis for Laminar Flow and Heat Transfer in Finite Rod Bundles," Chem. Eng. Comm., 51, pp. 129-140, 1987.

27. Todreas, N.E. and Kazimi, M.S., Nuclear Systems II Elements of Thermal Hydraulic Design, Taylor \& Francis, NY 1990.

28. YTZP ceramic by Coorstek, Inc., http://css.coorstek.com/qadcss/documents/cdsytzp.pdf, accessed on February $18^{\text {th }}, 2012$.

\section{NOMENCLATURE}

\begin{tabular}{|ll|}
\hline$a$ & cross-sectional area \\
$A$ & dimensionless area \\
$\mathrm{Bi}$ & Biot number \\
$c_{p}$ & specific heat \\
\hline
\end{tabular}




\begin{tabular}{|c|c|}
\hline$d$ & hydraulic diameter/tube inner diameter \\
\hline$D$ & heater diameter \\
\hline$D_{p}$ & pebble diameter \\
\hline$E$ & neutron fluence \\
\hline$f$ & friction factor \\
\hline $\mathrm{F}$ & Friction number \\
\hline$g$ & gravitational acceleration \\
\hline$G$ & mass flux \\
\hline $\mathrm{Gr}$ & Grashof number \\
\hline$h$ & heat transfer coefficient \\
\hline$k$ & thermal conductivity \\
\hline$K$ & form loss coefficient \\
\hline$l$ & length \\
\hline$L$ & dimensionless length \\
\hline $\mathrm{Nu}$ & Nusselt number \\
\hline$P$ & pitch \\
\hline $\operatorname{Pr}$ & Prandtl number \\
\hline$\dot{q}$ & volumetric heat generation rate \\
\hline Q & Heat source number \\
\hline$\dot{Q}$ & total decay power \\
\hline $\mathrm{R}$ & Richardson number \\
\hline$R$ & ratio between the model and the prototype \\
\hline $\mathrm{Re}$ & Reynolds number \\
\hline St & Stanton number \\
\hline$t$ & time/tube wall thickness \\
\hline$T$ & temperature \\
\hline$\Delta T$ & temperature difference between the hot and cold legs \\
\hline $\mathrm{T}^{*}$ & Time ratio number \\
\hline$u$ & velocity \\
\hline$U$ & dimensionless velocity \\
\hline$V$ & volume \\
\hline$W$ & shell wall spacing \\
\hline$y$ & transverse coordinate \\
\hline$Y$ & dimensionless transverse coordinate \\
\hline$z$ & axial coordinate \\
\hline$Z$ & dimensionless axial coordinate \\
\hline \multicolumn{2}{|c|}{ Greek symbols } \\
\hline$\alpha$ & thermal diffusivity \\
\hline$\beta$ & thermal expansion coefficient \\
\hline$\delta$ & conduction depth \\
\hline$\mu$ & dynamic viscosity \\
\hline$v$ & kinematic viscosity \\
\hline$\xi$ & wetted perimeter \\
\hline
\end{tabular}




\begin{tabular}{|ll|}
\hline$\rho$ & density \\
$\tau$ & dimensionless time \\
$\theta$ & dimensionless temperature \\
Subscripts & \\
average & averaged value \\
coating & coating graphite of the fuel pebble \\
$i$ & $i^{\text {th }}$ component \\
pebble & fuel pebble \\
$r$ & representative variable \\
$s$ & structure, solid \\
shell & spherical fuel shell \\
0 & reference value \\
\hline
\end{tabular}


Table 9: Dimensions of the fuel pebble and the TRISO particle

\begin{tabular}{|c|c|c|c|c|c|}
\hline \multicolumn{6}{|c|}{ Fuel pebble } \\
\hline $\begin{array}{c}\text { kraphite } \\
(\mathrm{mm})\end{array}$ & $\begin{array}{c}\text { Fuel zone } \\
\text { outer radius } \\
(\mathrm{mm})\end{array}$ & $\begin{array}{c}\text { Coating } \\
\text { thickness } \\
(\mathrm{mm})\end{array}$ & $\begin{array}{c}\text { Total } \\
\text { number of } \\
\text { TRISO }\end{array}$ & \multicolumn{2}{|c|}{$\begin{array}{c}\text { Volumetric fraction of } \\
\text { TRISO }\end{array}$} \\
\hline 9.92 & 12.5 & \multicolumn{2}{c|}{2.5} & 2,144 & \multicolumn{2}{c|}{$20 \%$} \\
\hline \multicolumn{7}{|c|}{ TRISO particle } \\
\hline Layer & $\begin{array}{c}\text { Fuel } \\
\text { kernel }\end{array}$ & $\begin{array}{c}\text { Porous } \\
\text { carbon }\end{array}$ & Pyrocarbon & $\mathrm{SiC}$ & Pyrocarbon \\
\hline $\begin{array}{c}\text { Radius } \\
(\mathrm{mm})\end{array}$ & 0.25 & 0.34 & 0.38 & 0.42 & 0.46 \\
\hline
\end{tabular}


Table 2: Definitions of dimensionless parameters

\begin{tabular}{|c|c|c|}
\hline & Reference values & $\begin{array}{l}\text { Dimensionless } \\
\text { parameters }\end{array}$ \\
\hline Velocity & $\begin{array}{l}u_{0}: \text { steady-state fluid velocity in the pipe (in } \\
\text { primary or secondary loop) }\end{array}$ & $\begin{aligned} U_{i} & =u_{i} / u_{0} \\
U_{r} & =u_{r} / u_{0}\end{aligned}$ \\
\hline \multirow[t]{2}{*}{ Length } & $\begin{array}{l}l_{0} \text { : vertical distance between the thermal centers } \\
\text { of the DHX and core for the primary loop or that } \\
\text { between the thermal centers of the NDHX \& DHX } \\
\text { for the secondary loop }\end{array}$ & $\begin{aligned} L_{i} & =l_{i} / l_{0} \\
Z & =z / l_{0}\end{aligned}$ \\
\hline & $\delta:$ conduction depth & $\begin{array}{c}\nabla^{* 2}=\delta^{2} \nabla^{2} \\
Y=y / d\end{array}$ \\
\hline Area & $\begin{array}{l}a_{0}: \text { cross-sectional area of the pipe (for the } \\
\text { primary or secondary loop) }\end{array}$ & $A_{i}=a_{i} / a_{0}$ \\
\hline Time & $l_{0} / u_{0}:$ characteristic fluid convection time & $\tau=t u_{0} / l_{0}$ \\
\hline Temperature & $\begin{array}{l}\Delta T_{0}: \text { temperature difference of the primary salt for } \\
\text { the primary loop or that of the secondary salt for the } \\
\text { secondary loop at steady state }\end{array}$ & $\theta=\left(T-T_{0}\right) / \Delta T_{0}$ \\
\hline
\end{tabular}


Table 3: Dimensions of the fuel pebble and the TRISO particle

\begin{tabular}{|c|c|c|c|c|c|}
\hline \multicolumn{6}{|c|}{ Fuel pebble } \\
\hline $\begin{array}{c}\text { kraphite } \\
(\mathrm{mm})\end{array}$ & $\begin{array}{c}\text { Fuel zone } \\
\text { outer radius } \\
(\mathrm{mm})\end{array}$ & $\begin{array}{c}\text { Coating } \\
\text { thickness } \\
(\mathrm{mm})\end{array}$ & $\begin{array}{c}\text { Total } \\
\text { number of } \\
\text { TRISO }\end{array}$ & \multicolumn{2}{|c|}{$\begin{array}{c}\text { Volumetric fraction of } \\
\text { TRISO }\end{array}$} \\
\hline 9.92 & 12.5 & \multicolumn{2}{c|}{2.5} & 2,144 & \multicolumn{2}{c|}{$20 \%$} \\
\hline \multicolumn{7}{|c|}{ TRISO particle } \\
\hline Layer & $\begin{array}{c}\text { Fuel } \\
\text { kernel }\end{array}$ & $\begin{array}{c}\text { Porous } \\
\text { carbon }\end{array}$ & Pyrocarbon & $\mathrm{SiC}$ & Pyrocarbon \\
\hline $\begin{array}{c}\text { Radius } \\
(\mathrm{mm})\end{array}$ & 0.25 & 0.34 & 0.38 & 0.42 & 0.46 \\
\hline
\end{tabular}


Table 4: Effective properties of the fuel pebbles

\begin{tabular}{|c|c|c|c|c|c|c|}
\hline Fluence $\left(\times 10^{25} \mathrm{n} / \mathrm{m}^{2}\right)$ & 0 & 0.1 & 0.2 & 0.5 & 1 & $3-8$ \\
\hline$k(\mathrm{~W} / \mathrm{m}-\mathrm{K})$ & 65.89 & 55.6 & 47.16 & 30.77 & 22.31 & 20.4 \\
\hline$c_{p}(\mathrm{~J} / \mathrm{kg}-\mathrm{K})$ & \multicolumn{7}{|c|}{1,635} \\
\hline$\rho\left(\mathrm{kg} / \mathrm{m}^{3}\right)$ & \multicolumn{7}{|c|}{1,894} \\
\hline
\end{tabular}


Table 5: Design parameters of the core in the HTDF

\begin{tabular}{|c|c|}
\hline$P / D$ & 1.6 \\
\hline$W / D$ & 1.4 \\
\hline Vessel diameter $(\mathrm{cm})$ & 9.53 \\
\hline Heater diameter $(\mathrm{cm} /$ inch $)$ & $1.91 / 0.75$ \\
\hline Heated length $(\mathrm{m})$ & 0.8 \\
\hline$h$ (type $\mathrm{II})\left(\mathrm{W} / \mathrm{m}^{2}-\mathrm{K}\right)$ & 200 \\
\hline$h$ type $\mathrm{I})\left(\mathrm{W} / \mathrm{m}^{2}-\mathrm{K}\right)$ & 320 \\
\hline$h_{\text {average }}\left(\mathrm{W} / \mathrm{m}^{2}-\mathrm{K}\right)$ & 251 \\
\hline
\end{tabular}


Table 6: Core and loop scaling results for the HTDF

\begin{tabular}{|c|c|c|c|c|c|c|c|c|}
\hline \multicolumn{3}{|c|}{ Fluence $\left(10^{25} \mathrm{n} / \mathrm{m}^{2}\right)$} & $\mathbf{0}$ & 0.1 & 0.2 & 0.5 & 1 & $3-8$ \\
\hline & Power $(\mathrm{kW})$ & & \multicolumn{6}{|c|}{10.0} \\
\hline \multicolumn{3}{|c|}{$\begin{array}{c}\text { Power ratio of the reactor nominal } \\
\text { power }(\%)\end{array}$} & \multicolumn{6}{|c|}{5.0} \\
\hline \multirow{9}{*}{$\begin{array}{l}\text { Primary } \\
\text { loop }\end{array}$} & \multicolumn{2}{|c|}{ Time ratio } & 1.04 & 1.14 & 1.23 & 1.42 & 1.60 & 1.81 \\
\hline & \multicolumn{2}{|c|}{ Length ratio } & 0.6 & 0.6 & 0.6 & 0.6 & 0.6 & 0.6 \\
\hline & \multirow{2}{*}{$\begin{array}{l}\text { Hydraulic } \\
\text { diameter } \\
\text { ratio in core }\end{array}$} & $\begin{array}{c}\text { From } \\
\text { scaling }\end{array}$ & 0.38 & 0.42 & 0.45 & 0.52 & 0.59 & 0.67 \\
\hline & & From & & & & & & \\
\hline & \multicolumn{2}{|c|}{$\delta$ ratio in core } & 0.29 & 0.32 & 0.34 & 0.39 & 0.44 & 0.50 \\
\hline & \multicolumn{2}{|c|}{ Velocity ratio } & 0.58 & 0.52 & 0.49 & 0.42 & 0.38 & 0.33 \\
\hline & \multirow{2}{*}{\multicolumn{2}{|c|}{ Area ratio }} & 0.27 & 0.36 & 0.45 & 0.69 & 0.99 & 1.43 \\
\hline & & & 0.39 & 0.32 & 0.28 & 0.21 & 0.16 & 0.13 \\
\hline & \multicolumn{2}{|c|}{$\begin{array}{l}\text { Heat source number } \\
\text { ratio }\end{array}$} & 104 & 140 & 174 & 267 & 381 & 552 \\
\hline \multirow{5}{*}{$\begin{array}{l}\text { Secondary } \\
\text { loop }\end{array}$} & \multicolumn{2}{|c|}{ Time ratio } & 1.04 & 1.14 & 1.23 & 1.42 & 1.60 & 1.81 \\
\hline & \multicolumn{2}{|c|}{ Length ratio } & 0.6 & 0.6 & 0.6 & 0.6 & 0.6 & 0.6 \\
\hline & \multicolumn{2}{|c|}{ Velocity ratio } & 0.58 & 0.52 & 0.49 & 0.42 & 0.38 & 0.33 \\
\hline & \multirow{2}{*}{\multicolumn{2}{|c|}{$\begin{array}{c}\text { Area ratio } \\
\Delta T \text { ratio }\end{array}$}} & 0.17 & 0.23 & 0.29 & 0.45 & 0.64 & 0.93 \\
\hline & & & 0.64 & 0.53 & 0.46 & 0.34 & 0.27 & 0.21 \\
\hline \multirow{5}{*}{ Air loop } & \multicolumn{2}{|c|}{ Time ratio } & 1.04 & 1.14 & 1.23 & 1.42 & 1.60 & 1.81 \\
\hline & \multicolumn{2}{|c|}{ Length ratio } & 0.6 & 0.6 & 0.6 & 0.6 & 0.6 & 0.6 \\
\hline & \multicolumn{2}{|c|}{ Velocity ratio } & 0.58 & 0.52 & 0.49 & 0.42 & 0.38 & 0.33 \\
\hline & \multicolumn{2}{|c|}{ Area ratio } & 0.15 & 0.21 & 0.26 & 0.40 & 0.57 & 0.82 \\
\hline & \multicolumn{2}{|c|}{$\Delta T$ ratio } & 0.56 & 0.46 & 0.40 & 0.30 & 0.24 & 0.18 \\
\hline
\end{tabular}


Table 7: DHX and NDHX scaling results for the HTDF

\begin{tabular}{|c|c|c|c|c|c|c|c|}
\hline \multicolumn{2}{|c|}{ Fluence $\left(10^{25} \mathrm{n} / \mathrm{m}^{2}\right)$} & $\mathbf{0}$ & 0.1 & 0.2 & 0.5 & 1 & $3-8$ \\
\hline \multirow{3}{*}{ DHX shell side } & $\delta$ ratio & $\mathbf{1 . 1 1}$ & 1.16 & 1.20 & 1.29 & 1.37 & 1.46 \\
\cline { 2 - 8 } & $D_{h}$ ratio & $\mathbf{1 . 2 5}$ & 1.31 & 1.36 & 1.46 & 1.55 & 1.65 \\
\cline { 2 - 8 } & $h$ ratio & $\mathbf{0 . 9 8}$ & 0.94 & 0.90 & 0.84 & 0.79 & 0.75 \\
\hline \multirow{3}{*}{ DHX tube side } & $\delta$ ratio & $\mathbf{1 . 1 1}$ & 1.16 & 1.20 & 1.29 & 1.37 & 1.46 \\
\cline { 2 - 8 } & $D_{h}$ ratio & $\mathbf{1 . 3 2}$ & 1.38 & 1.44 & 1.54 & 1.64 & 1.74 \\
\cline { 2 - 8 } & $h$ ratio & $\mathbf{0 . 9 8}$ & 0.94 & 0.90 & 0.84 & 0.79 & 0.75 \\
\hline \multirow{3}{*}{ NDHX tube } & $\delta_{\text {ratio }}$ & $\mathbf{1 . 1 3}$ & 1.19 & 1.23 & 1.32 & 1.40 & 1.49 \\
\cline { 2 - 8 } & $D_{h}$ ratio & $\mathbf{1 . 3 1}$ & 1.37 & 1.42 & 1.53 & 1.62 & 1.73 \\
\cline { 2 - 8 } & $h$ ratio & $\mathbf{0 . 9 8}$ & 0.93 & 0.90 & 0.84 & 0.79 & 0.74 \\
\hline \multirow{3}{*}{ NDHX air side } & $\delta_{\text {ratio }}$ & $\mathbf{1 . 1 3}$ & 1.19 & 1.23 & 1.32 & 1.40 & 1.49 \\
\cline { 2 - 8 } & $D_{h}$ ratio & $\mathbf{1 . 0 1}$ & 1.06 & 1.10 & 1.18 & 1.26 & 1.34 \\
\cline { 2 - 8 } & $h$ ratio & $\mathbf{0 . 9 8}$ & 0.93 & 0.90 & 0.84 & 0.79 & 0.74 \\
\hline
\end{tabular}


Table 8: Design results summary for the HTDF

\begin{tabular}{|c|c|c|c|c|}
\hline & Parameters & $\begin{array}{l}\text { Value for } \\
\text { Prototype }\end{array}$ & $\begin{array}{r}\text { Value for } \\
\text { Experiment }\end{array}$ & Ratio \\
\hline & $\dot{Q}$ & $200 \mathrm{~kW}$ & $10.0 \mathrm{~kW}$ & 0.05 \\
\hline & Primary Loop & $2.28 \mathrm{~m}$ & $1.37 \mathrm{~m}$ & 0.6 \\
\hline$l_{o}$ & Secondary Loop & $2.3 \mathrm{~m}$ & $1.38 \mathrm{~m}$ & 0.6 \\
\hline & Air Loop & $10.43 \mathrm{~m}$ & $6.26 \mathrm{~m}$ & 0.6 \\
\hline & Primary Loop & $0.054 \mathrm{~m} / \mathrm{s}$ & $0.031 \mathrm{~m} / \mathrm{s}$ & 0.58 \\
\hline$u_{o}$ & Secondary Loop & $0.059 \mathrm{~m} / \mathrm{s}$ & $0.034 \mathrm{~m} / \mathrm{s}$ & 0.58 \\
\hline & Air Loop & $0.346 \mathrm{~m} / \mathrm{s}$ & $0.200 \mathrm{~m} / \mathrm{s}$ & 0.58 \\
\hline & Primary Loop & $42.2 \mathrm{~s}$ & $43.9 \mathrm{~s}$ & 1.04 \\
\hline$l_{o} / u_{o}$ & Secondary Loop & $7.2 \mathrm{~s}$ & $7.5 \mathrm{~s}$ & 1.04 \\
\hline & Air Loop & $30.2 \mathrm{~s}$ & $31.4 \mathrm{~s}$ & 1.04 \\
\hline & Primary Loop & $45^{\circ} \mathrm{C}$ & $17.6^{\circ} \mathrm{C}$ & 0.39 \\
\hline$\Delta T_{o}$ & Secondary Loop & $50^{\circ} \mathrm{C}$ & $32.1^{\circ} \mathrm{C}$ & 0.64 \\
\hline & Air Loop & $60^{\circ} \mathrm{C}$ & $33.5^{\circ} \mathrm{C}$ & 0.56 \\
\hline & Primary Loop & $150 \mathrm{~mm}$ & $78.0 \mathrm{~mm}$ & 0.52 \\
\hline pipe & Secondary Loop & $150 \mathrm{~mm}$ & $62.7 \mathrm{~mm}$ & 0.42 \\
\hline & Air Loop & $2819 \mathrm{~mm}$ & $1109.7 \mathrm{~mm}$ & 0.39 \\
\hline$\dot{m}$ & Primary Loop & $1.84 \mathrm{~kg} / \mathrm{s}$ & $0.302 \mathrm{~kg} / \mathrm{s}$ & 0.16 \\
\hline & Secondary Loop & $2.12 \mathrm{~kg} / \mathrm{s}$ & $0.299 \mathrm{~kg} / \mathrm{s}$ & 0.14 \\
\hline & Air Loop & $3.31 \mathrm{~kg} / \mathrm{s}$ & $0.296 \mathrm{~kg} / \mathrm{s}$ & 0.089 \\
\hline
\end{tabular}


Figure 1

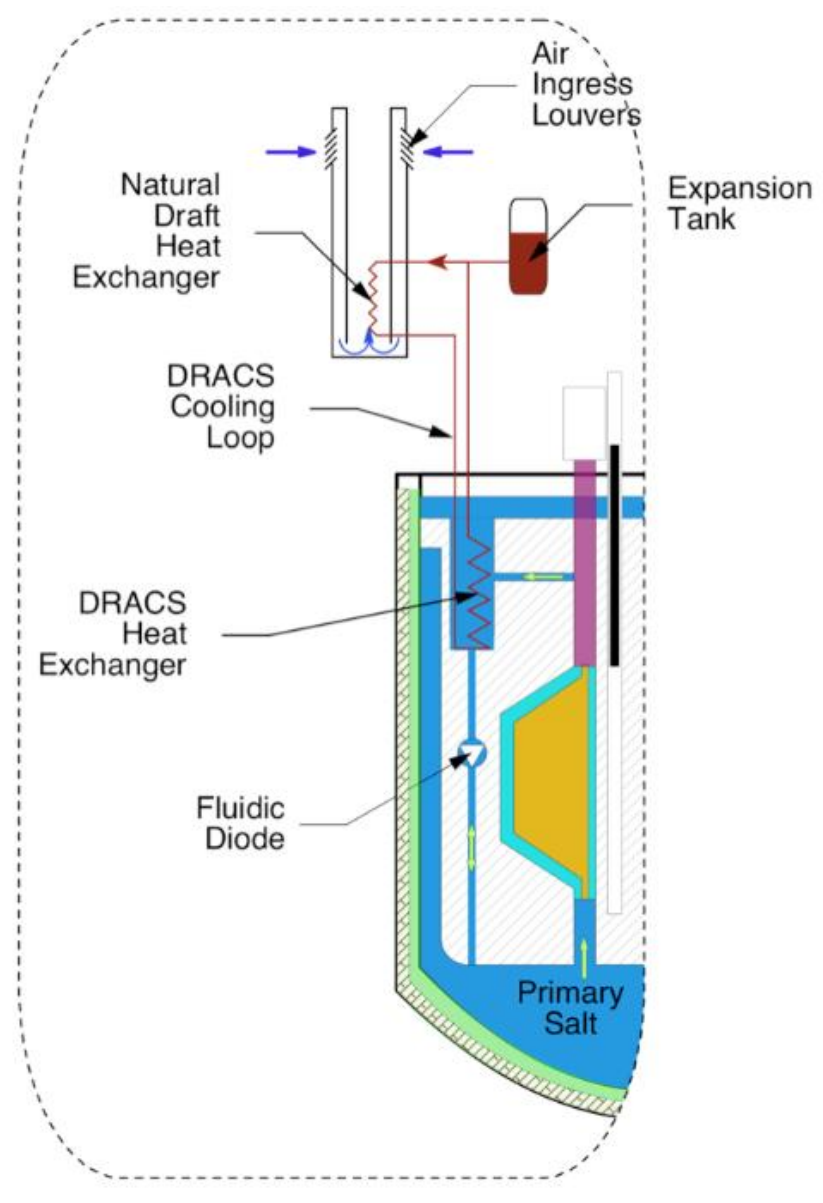

Figure 1: Schematic of the DRACS [6] 
Figure 2

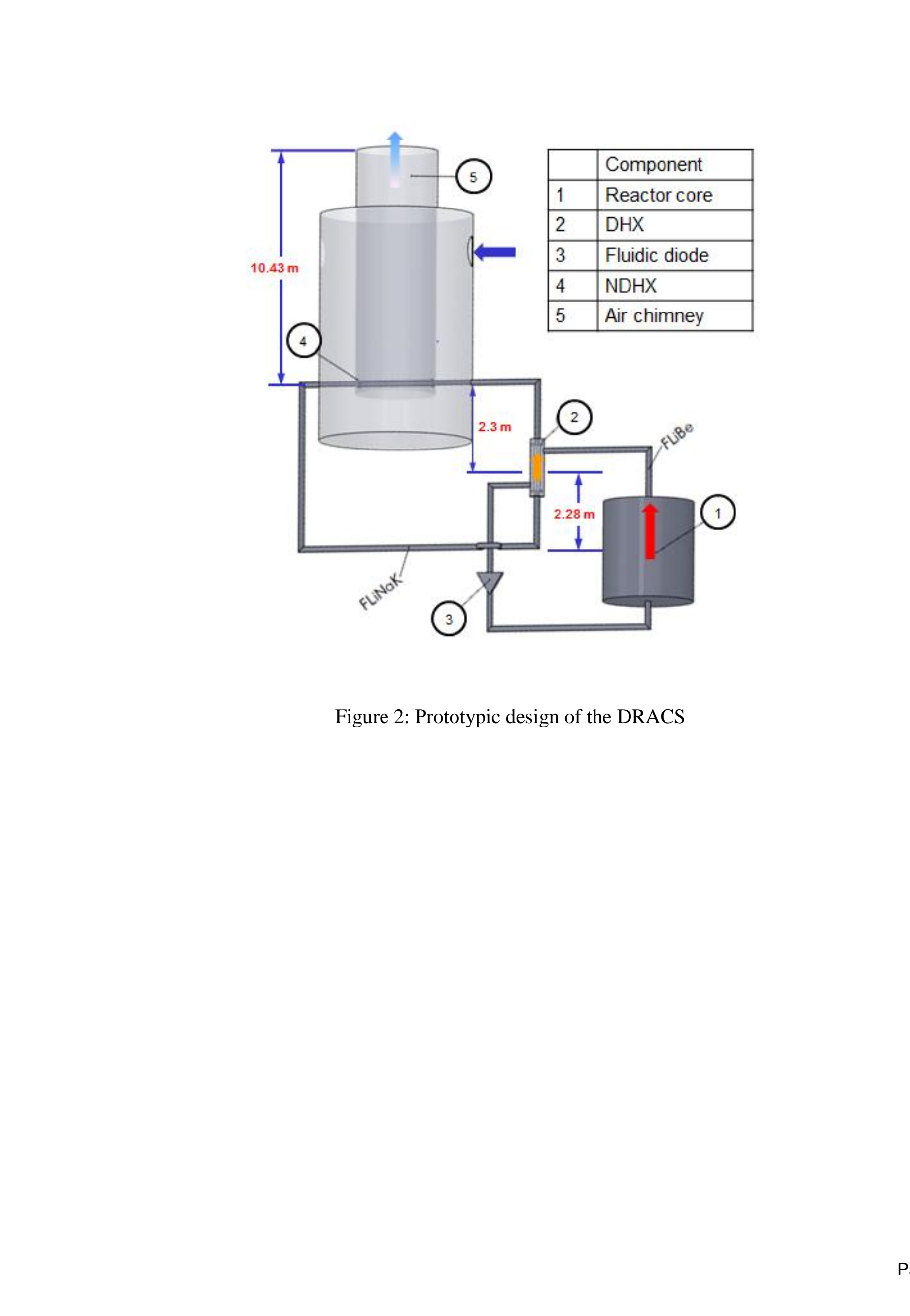

Figure 2: Prototypic design of the DRACS

Figure 2: Prototypic design of the DRACS

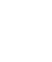

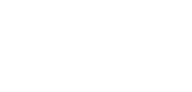
of 43 

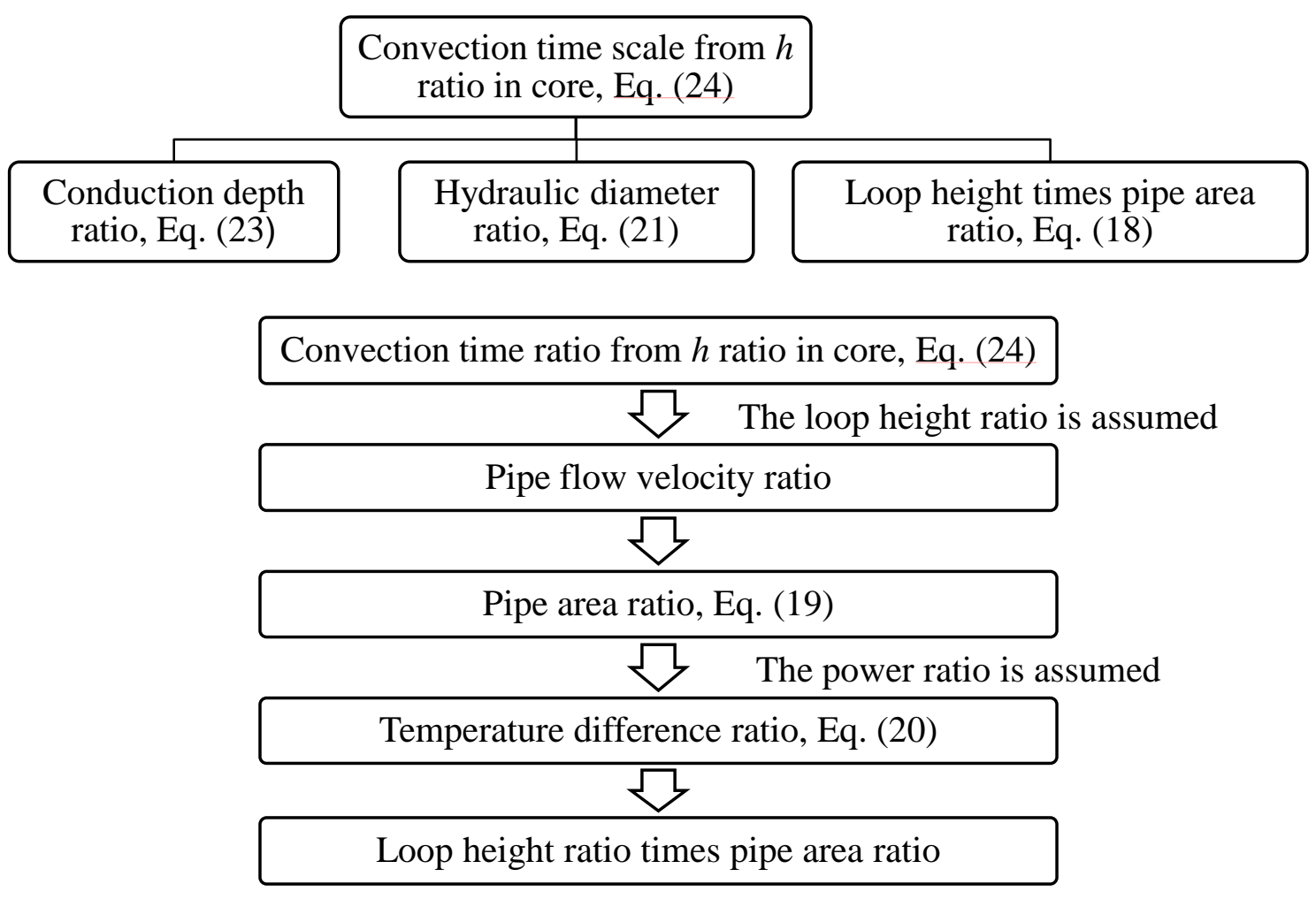

Figure 3: Flow charts for the core and primary loop scaling 


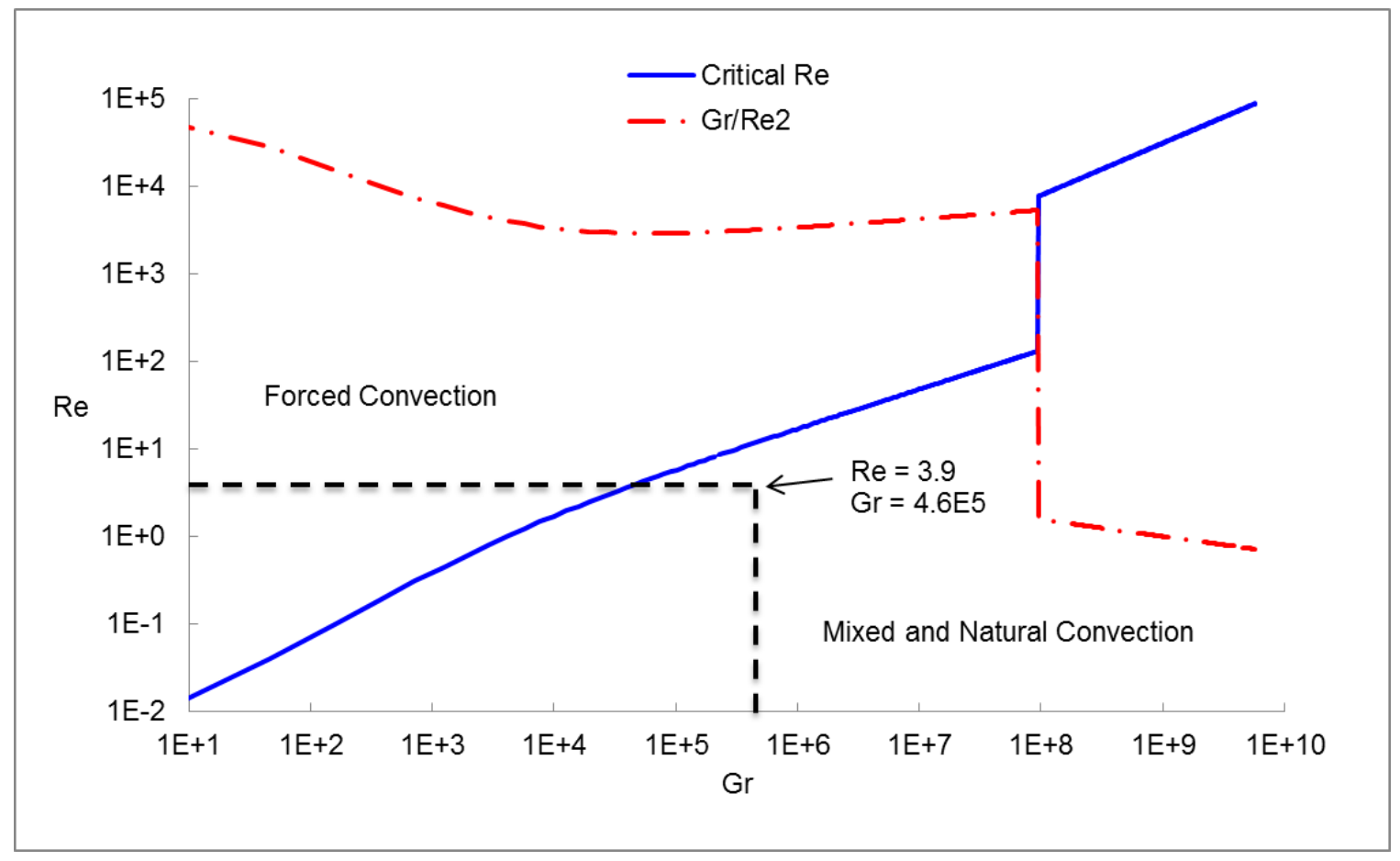

Figure 4: Relation between the critical Reynolds and Grashof numbers for flow transition from the mixed to forced convection 

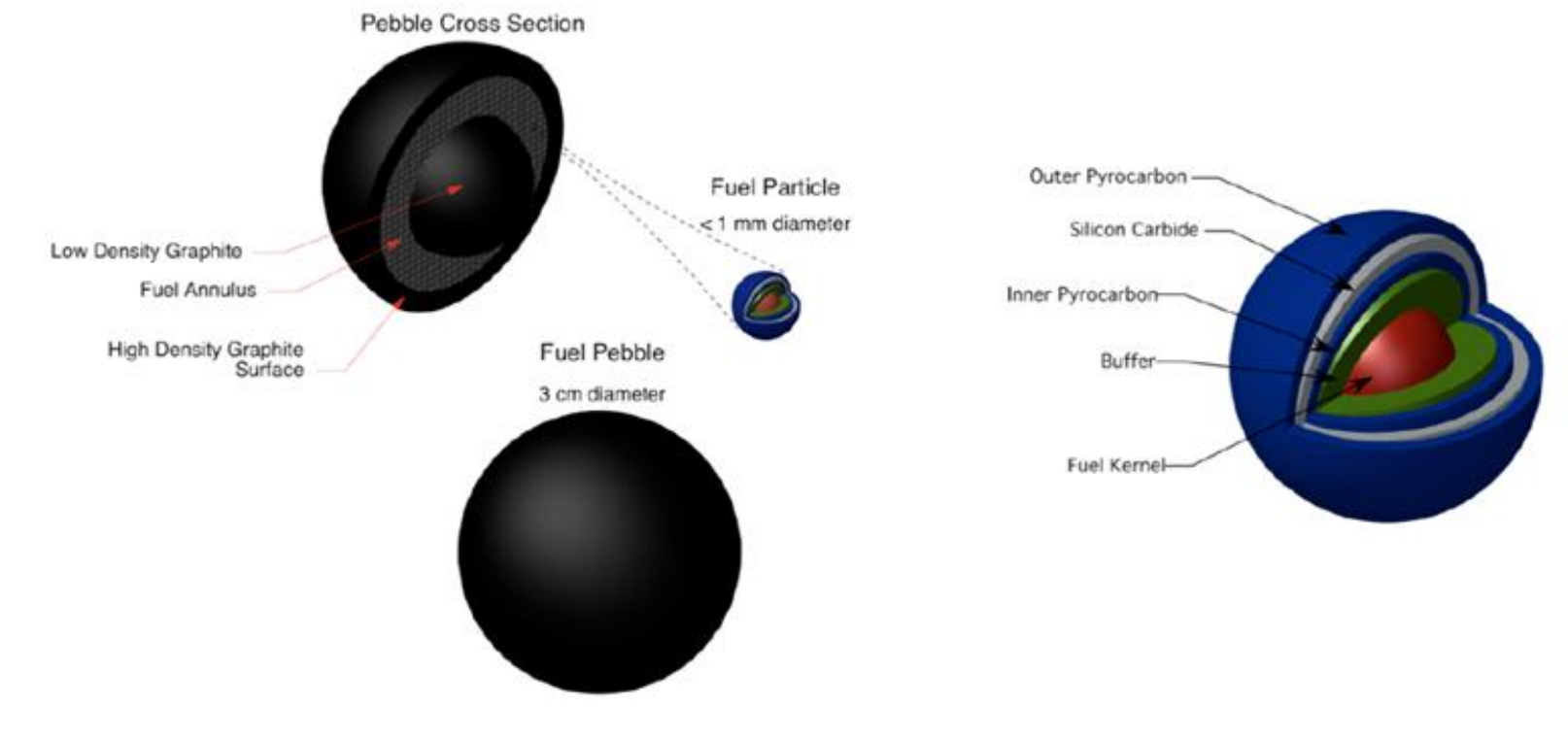

Figure 5: The structure of the fuel pebble and TRISO particle [11]

.

Figure 5

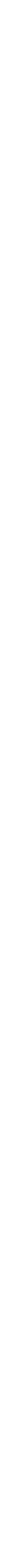

5

5




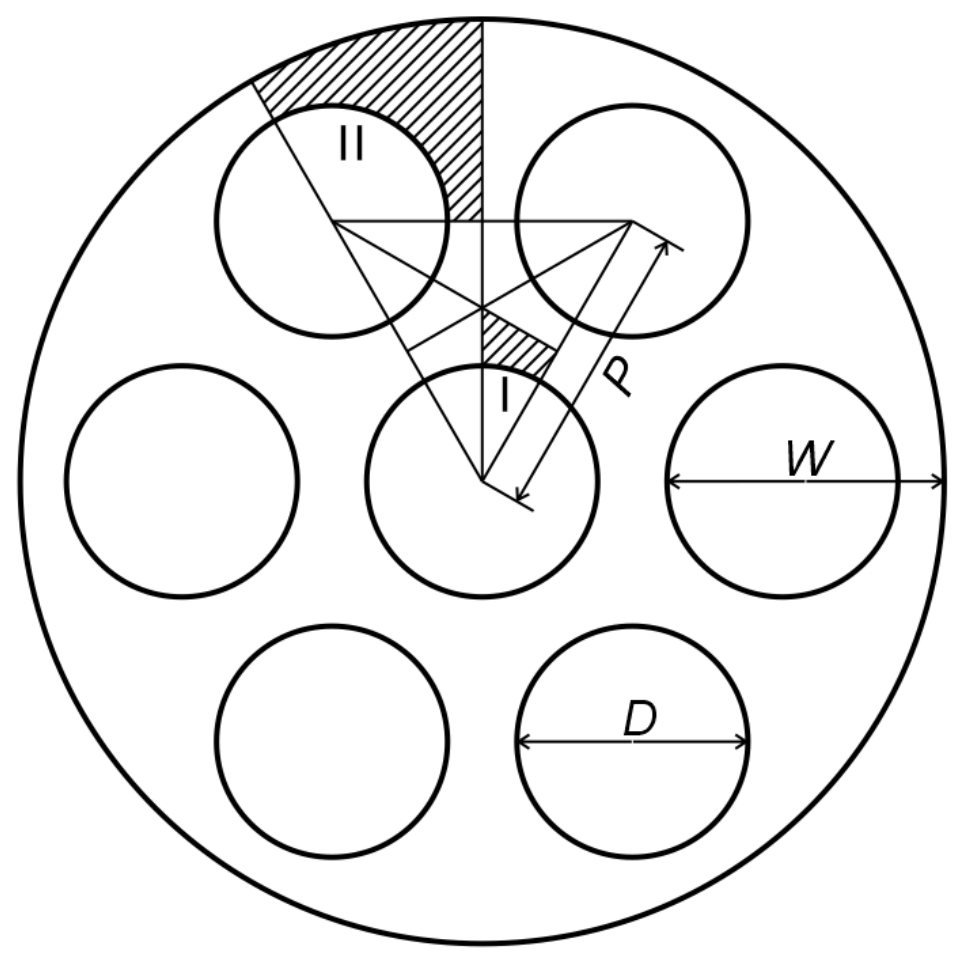

Figure 6: Core design in the HTDF (I: interior sub-channel; II: wall sub-channel; $D$ : rod diameter; $P$ : rod pitch; $W$ : shell-to-wall spacing ) 